\title{
El consumo y la experiencia de la modernidad en América Latina
}

Roberto Hernández Araya

Facultad de Administración y Economía-

Universidad de Santiago de Chile

\section{Resumen}

El artículo destaca el lugar primordial del consumo Palabras clave: en la configuración del significado de la experiencia moderna, observando con especial atención el camino propio que muestra esta articulación en América Latina. consumo, modernidad, elección, individuo, ciudadanía $\mathrm{Al}$ respecto, el análisis se refiere a algunas propuestas interpretativas originadas en la región, tanto de tenor crítico como de carácter generativo, postulándose, en este último caso, la necesidad de concebir al consumo como una dimensión cultural indispensable para la convivencia democrática en nuestras sociedades.

\section{Abstract}

\section{Consumption and modernity in Latin America}

The article highlights the essential place of consumption in shaping the meaning of modern experience, looking closely at the suitable path shown by this articulation in Keywords: consumption, modernity, choice, individual, citizenship Latin America. In this regard, the analysis refers to some 
interpretative proposals originated in the region, some of them critical and others generative, postulating, in the latter case, the need to conceive the consumption as an indispensable cultural dimension for democratic coexistence in our societies.

\section{Resumo}

\section{O consumo e a experiência da modernidade na} América Latina

$\mathrm{O}$ artigo destaca o principal lugar de consumo na configuração do significado da experiência moderna, observando com atenção especial o próprio caminho

Palavras-chave: consumo, modernidade, escolha, indivíduo, cidadania mostrado por esta articulação na América Latina. Nesse sentido, a análise refere-se a algumas propostas interpretativas originadas na regiáo, de natureza crítica e generativa, postulando-se, neste último caso, a necessidade de conceber o consumo como uma dimensáo cultural indispensável para a convivência democrática em nossas sociedades.

\section{Elegir la vida}

Como el mayor intruso, pero también como el más discreto, y realizando un ejemplar ejercicio de la «desatención cortés» que reclama Erving Goffman para nuestros encuentros cotidianos con desconocidos - evitando observarlos invasivamente-, me encontraba escuchando la conversación de dos jóvenes que aparentemente eran compañeros de trabajo, los que hacían más interesante mi habitual viaje vespertino a casa en el tren subterráneo. Uno de ellos se encontraba sorprendido y algo decepcionado, pues el otro acababa de «confesar» que no tenía más planes para sus vacaciones, próximas a iniciarse, que quedarse descansando en su casa en Santiago. Algunos minutos antes, quien ahora se mostraba disconforme con la respuesta de su compañero, había conseguido capturar mi — disimuladaatención con una entusiasta y gestual descripción de sus planes de asueto, que contemplaban una calculada cronología orientada al aprovechamiento de los días considerados al efecto, en la que se entrelazaba coherentemente "un viaje a Buenos Aires durante algunos días», «la 
visita a familiares en el sur» en seguida — «una vez llegando»—, para luego «relajarse» en la playa en las postrimerías de su movediza salida.

Con una expresión fácilmente inteligible y por lo mismo, de probable proyección universal —que involucra simultáneamente inclinar hacia un lado la cabeza, encogerse de hombros, sonreír solo ligeramente y asegurar empática preocupación con la mirada-, el sujeto con el proyecto «afanoso» de vacaciones le dice a su acompańante: «Bueno, seguramente tienes pensado aprovechar de hacer cosas pospuestas, como ir al cine, ver unas series — de televisión — o salir a comer, ¿O no?», dando la impresión de que solicitaba cierta complicidad a su contertulio para que confirmara, al menos, algunas de estas últimas expectativas proferidas en torno a cómo podían "aprovecharse» esos días. Lamentablemente, no conseguí mantenerme atento a esa interesante conversación durante mucho tiempo más, - por ejemplo, podría haber esperado un momento para comprobar los efectos de la potencia coercitiva de las expectativas de una persona sobre la otra-, ya que lo que acababa de escuchar resonaba con gran familiaridad en relación con mis propios recuerdos y emociones, y acabó por conducirme a pensamientos sobre mis propias vivencias. En algunas ocasiones y en distintos contextos - laborales, entre amigos o conversando con parientes-, tal como acababa de hacer ese des- conocido junto a mí, también me había correspondido plantear que mi horizonte recreativo veraniego se encontraba, en realidad, totalmente abierto, desprogramado e indiferente de "pasar un tiempo fuera", obteniendo a cambio, asimismo, reacciones asociadas a un arco evaluativo amplio que oscilaba desde la compasión por lo que parecía interpretarse como una situación de carestía económica, hasta la indulgencia risueña frente a «otra de mis extravagancias".

Pero en un sentido más relevante, al igual que sucede cuando participo en ese tipo de conversaciones, el diálogo entre los pasajeros me recordó — como otras veces- el libro de David Chaney titulado Estilos de vida (1996), donde, al servicio de la temática que busca abordar, el autor concibe al consumo como estrechamente ligado con las "pautas sociales de ocio", es decir, con expectativas referidas al «control y utilización del tiempo de maneras personalmente significativas» (1996:24). Sin duda, esas «exigencias» sobre las formas de ocupar «el tiempo libre» que resultarían satisfactorias, elegibles y provechosas, todas mediadas por compras, viajes y concurrencias a espacios de esparcimiento, declaran algo acerca de ciertas maneras extendidas de pensar y sentir que se encuentran ampliamente aceptadas, que operan como principios de discriminación en torno a nuestras decisiones en el mercado y que, también en estos casos recién descritos, seguramente 
nos hacían acreedores, tanto al «renegado del metro» como a mi persona, del rótulo de "consumidores fallidos».

Se trata, además, de conversaciones e ideas que nos asaltan en la actualidad prácticamente en cualquier espacio y con distintos expedientes. Considérese que el diálogo descrito tuvo lugar en esa interesantísima cápsula de observación urbana que es el tren subterráneo, donde la —en apariencia - siempre amable invitación a comprar me acompañaría el resto del viaje, incluso totalmente ajena a mi disposición a seguir o no fisgoneando en la conversación entre esos compañeros de trabajo. Ahí mismo, en carteles retroiluminados, personas con alegres expresiones faciales me invitaban a "no pensar más y decidirme a comprar cómodos departamentos» - generalmente con pocos dormitorios- e, incluso, a cambiar mi «administradora de fondos de pensiones» por otras agencias que aceptaban menores imposiciones, de manera de que pudiese contar con más dinero a fin de mes. ¿Para hacer qué cosa?

Para Zygmunt Bauman (2000), mensajes como el anterior, o bien, el tipo de eslogan «más dinero en los bolsillos del contribuyente», reclaman un supuesto derecho del consumidor a ejercer «su elección", un derecho ya internalizado y transformado en vocación de vida. Para Bauman, los hábitos de consumo impuestos por las sociedades contemporáneas reposarían sobre los hombros de los propios sujetos igual que las vocaciones religiosas-, esto es, como máximas "éticas», como obligaciones internalizadas que comportan la imposibilidad de vivir de cualquier otra forma. Como nunca antes, vivir una vida significativa hoy implicaría visitar periódicamente el mercado, buscando siempre experiencias novedosas, sin aferrarse o deberle fidelidad a nada — en medio de una pluralidad de alternativas de compra que generan la sensación de una "libertad de elegir», no obstante su incongruencia con la «obligación» de participar en el mercado que todas ellas presuponen-. Así, de acuerdo con este autor, aunque el individuo en nuestros tiempos aparentemente se habría liberado de la opresión de las rutinas que ejercían las viejas sociedades, reapareciendo glorioso como un homo eligens (sic), en lugar de libertad, este en realidad habría conseguido una vida colonizada por los mercados, un contexto en el cual «los miembros de una sociedad de consumidores son ellos mismos bienes de consumo", que aumentan o disminuyen su valor de mercado según adquieran atractivos productos que les significan lugares de privilegio o de exclusión social. Sin pretender entrar aún en el debate en torno al tenor problemático de posiciones como la anterior, que hasta cierto punto sigue un curso similar al cuestionamiento recibido en su momento por autores como Horkhaimer, Adorno, Marcuse y compañía, acusados -con 
distinto ímpetu- de establecer discutibles distinciones entre tipos «reales» $\mathrm{y}$ «falsos» de individualidad, de necesidades, etc., lo que resulta especialmente pertinente en el planteamiento de Bauman se refiere a la recién sugerida jerarquía superior que el autor polaco otorga a la práctica de la «elección» en su argumento sobre el consumo. En efecto, con la particularidad de que presta especial atención al contexto latinoamericano, el presente análisis comparte el interés primordial de Bauman en examinar el modo en que las «modernas» exigencias sociales de versatilidad, subjetividad, libertad y autonomía personal encontrarían actualmente su más claro indicio de concreción en la «acción de elegir»-virtualmente, el signo de salvación adecuado en el reino de la racionalidad formal, jugueteando con la tesis weberiana- y que sería en la esfera del consumo donde mejor se plasma esta pauta. Como sucede a propósito de la situación relatada más arriba, ello explicaría que en ocasiones nos quede la sensación de que consumir pasa a ocupar un segundo lugar de importancia frente al ejercicio de la elección misma. Se trataría de un elemento constitutivo de nuestra identidad social, a veces opresivamente sublimado, que en caso de no encontrarse presente o de practicarse deficitariamente, es observado con abierta inquietud o menosprecio. No «salir» de vacaciones, no escoger algún producto al interior del bien provisto supermercado del ocio, constituye, al respecto, una provocación simbólica inaceptable.

\section{Las trayectorias de un imperativo moderno}

¿Pero corresponde a una cuestión omnímoda, que avanza y opera por igual en todos lados? Ciertamente, cuando se plantea la existencia de un «moderno» patrón generalizado cuyo centro es la elección, nos encontramos con un problema conocido para el pensamiento social inspirado en lo que ocurre en esta parte del mundo: dicha posición parece encontrarse -al menos inicialmente- cargada de un marcado y cómodo acento epistémico circunscrito a enfoques de la realidad y supuestos conceptuales que estriban fundamentalmente en la modernidad europea. En otras palabras, siendo rigurosos, es preciso hacerse cargo de los alcances en nuestro planteamiento de lo que Escobar (2003) denomina un «enfoque intramoderno», cuestión que asumida desprevenidamente podría plantear dificultades para reconocer la transición entre esa «modernidad paradigmática» y la realidad de múltiples formaciones culturales, como las que encontramos en América Latina. ¿Pero cómo evitar, entonces, esa interpretación universalizante de la modernidad cuando hablamos de una extendida importancia cultural de la elección? Veamos en seguida de qué manera podemos interpretar esa usual y fastidiosa confusión entre 
la universalidad abstracta y el mundo concreto derivado de la posición europea como «centro» —además de Escobar, 2003, véase Dussel, 2000; Quijano, 200I, entre otros ${ }^{1}$ - acudiendo a una mirada que, junto con hacerse cargo de este problema, permite mantener el eje de nuestra reflexión en el consumo.

Aunque paradójicamente su contribución se origina cuando intenta redefinir esta gruesa categoría para pensar en Europa, resulta fundamental el aporte de Cornelius Castoriadis - especialmente en El Mundo Fragmentado (2008)- para avanzar en la superación de la tendencia a agotar «la modernidad» solo en procesos socioculturales europeos y comenzar a vislumbrarla en relación con posibles trayectorias y acontecimientos alternativos. Tal es la valiosa opción que entrega su idea acerca de que aquello que en realidad define un período de la humanidad se debe buscar en las «significaciones imaginarias» que lo caracterizan, advirtiendo que para la Europa posterior al medioevo han resultado cruciales las distintas configuraciones y relaciones recíprocas entre el proyecto de autonomía -tanto individual como colectiva, impulsado por la democracia y el conocimiento científico- y el proyecto de dominio racional — sobre la naturaleza y las cosas, identificado con la lógica del capitalismo-. Se trata de otro de los alcances de su propuesta más amplia de entender a la imaginación como una fuente primaria de la creación humana, materia que Castoriadis ya había vinculado en su obra (1975) con el desarrollo de una autonomía reflexiva que resultaría crucial para que las sociedades consigan trascender los determinismos históricos y religiosos «heredados» que les impiden pensar y decidir sobre el futuro deseado.

Es así que podría situarse al interior de un marco de análisis distinto al habitual, el anunciado encomio del individuo - $y$ sus decisiones- que con frecuencia se concibe impulsado por cada uno de los

1 En rigor, no debe olvidarse que varias de las ideas que nos informan sobre el "modo de ser de hoy" -lo moderno, en sentido etimológico- y acerca de sus procesos más específicos asociados como el avance de ciertas lógicas culturales de consumo-, necesitan, también, rendir cuentas en torno a cuestiones como su lugar de enunciación o la posible subalternización del conocimiento y la cultura que esas proposiciones podrían suponer acontecidas en una "periferia" -en este caso, latinoamericana- entendida como un objeto constituido. Tales discusiones, que en especial ocupan a los proyectos de los estudios poscoloniales y subalternos, sin duda, se entrelazan vivamente con la presente reflexión y, aun sin apoderarse por completo de ella, explican en buena medida su intento algo descarriado -empleando fuentes y referencias poco convencionales, aunque, se espera, más pertinentes- de pensar la cuestión de la centralidad de la elección en contextos plurales de clasificación cultural y de diversa valoración etnohistórica de los bienes simbólicos, como los que encontramos en nuestra región. 
procesos transformadores de la cultura y la sociedad europea cristalizados con mayor fuerza a partir del siglo XVII, tanto en la esfera política — con la revolución que significó el liberalismo político y el nuevo estatus jurídico con el que este movimiento protege al individuo-, como a nivel epistemológico -también, con un ser humano que se redefine ahora como la medida última de cuánto puede conocer y que, al efecto, cuenta con un «método» engendrado mediante la feliz e inédita alianza entre empirismo y racionalismo-, y en el ámbito económico — con la instalación del capitalismo industrial y comercial, supuestamente favorable al libre emprendimiento individual y abierto a la participación en el mercado-.

Enriqueciendo la visión anterior, para Castoriadis, la concepción de «individuo» no puede separarse de la idea de autonomía. Mientras el proyecto de dominio racional que «encarna en el capitalismo» aparece como una nueva significación en el imaginario social solo a partir de lo que este autor denomina la «época crítica»-la modernidad europea-, el proyecto de autonomía, «el actuar reflexivo de una razón que se crea en un movimiento sin fin, de una manera a la vez individual y social» (2008:104), lo precedería largamente en la historia, remontándose al mundo helénico. Esta idea cardinal involucraría dos aspectos del individuo, uno externo y otro interno. De una parte, el individuo se encuentra constituido por imaginarios instituyentes, por hechos culturales generales que recibe de la sociedad como un colectivo anónimo que lo precede y que en él mismo se fijan, explicitan y recrean. Pero, de otra parte, y esto resulta especialmente sugerente para nuestra reflexión, el individuo posee una dimensión de subjetividad, es decir, cuenta con la capacidad de tomar conciencia de su relación con la realidad, del espacio del que dispone para producirla e incluso para alterarla. Castoriadis lo explica así:

Dicho de otro modo, la formación de una instancia reflexiva y deliberante, de la verdadera subjetividad, libera la imaginación radical del ser humano singular como fuente de creación y de alteración y le permite alcanzar una libertad efectiva, que presupone ciertamente la indeterminación del mundo psíquico y la permeabilidad en su seno, pero conlleva también el hecho de que el sentido simplemente dado deja de ser planteado (lo cual sucede siempre cuando se trata del mundo social-histórico), y existe elección del sentido no dictado con anterioridad" -la palabra subjetividad es destacada por propio autor. (Castoriadis, 2008:105)

De tal forma que esta dimensión interna del individuo se encontraría estrechamente ligada a la cuestión de la «elección del sentido». Como señala uno de sus comentaristas (Cristiano, 2012:25), Castoriadis se refiere al «sentido» en sus 
-espinosas- acepciones de «significado ordenador», una noción más bien antropológica, y también como «impulso y valor», con lo que se imprime una mirada, si se quiere, más filosófica y que nos informa bastante acerca de la relación estrecha que existiría para el autor entre sentido y autonomía, especialmente si recordamos que define a esta última como un «movimiento reflexivo sin fin»-además, nótese que la misma formulación de «significación imaginaria» remite a una capacidad de creación de sentido accesible a los individuos de cada sociedad histórica-. Para Castoriadis, sin embargo, el problema es que el avance contemporáneo del dominio racional sin resistencias en la política, en las ideas $y$ en el arte, o lo que es equivalente, la pérdida de fuerza e importancia de las significaciones imaginarias alternativas a la expansión del «dominio técnico racional ilimitado», habrían propiciado la entrada, al menos de las que denomina «sociedades occidentales», en una nueva fase a partir de la segunda mitad del siglo $\mathrm{xx}$, donde las significaciones centrales de lo social pasan a caracterizarse por su «insignificancia» y por promover una «retirada al conformismo». Sin duda simplificando sus premisas, pero en el mismo movimiento intentando rescatar lo fundamental de su propuesta en relación con la cuestión que nos ocupa, esta sería la versión de Castoriadis sobre el fenómeno contemporáneo del resquebrajamiento de lo social y de su par complementario, la privatización de la vida.

En un contexto de debilitamiento de las referencias sociales tradicionales - familia, escuela, política- y en el cual el propio capitalismo enfrentaría hoy su mayor crisis a raíz de una escalada global del desempleo y del compromiso ecológico que implica su operación, Castoriadis explica que no podemos esperar construirnos individualmente a partir de nuestra relación con una sociedad que pierde su poder instituyente sobre quienes la componen, ni tampoco podemos hacerlo colectivamente, debido a la también debilitada fuerza vinculante de lo social en tanto "cosmos de sentido". Si se aspira a que al interior de la sociedad cada individuo sea libre de crear para su vida el sentido que quiera $-o$ que pueda-, admitiendo sin duda que es absurdo pensar que esto se consiga fuera de todo contexto y condicionamiento histórico-social, tal objetivo se vería seriamente dificultado cuando se encuentra anulada la capacidad de cuestionar todo sentido dado de antemano, cuando «no puede liberarse la creación de significaciones nuevas». Cuando, en definitiva, peligra el proyecto de autonomía. Las significaciones contemporáneas menos afectadas en este contexto serían aquellas de signo racionalizador —en opinión de Castoriadis, encabezadas notoriamente por las imágenes y prácticas asociadas al consumo-, que aunque parecen ajustarse con «extraordinaria flexibilidad» a cada 
carestía individual o colectiva, se encontrarían finalmente impedidas de superar las insuficiencias y vacíos que prometen resolver con objetos y técnicas concretas y, por el contrario, terminarían por profundizar la crisis del proyecto de autonomía. El propio autor, en otro de sus textos, lo explica con particular dureza:

Del mismo modo, en el Occidente contemporáneo, el «individuo libre, soberano, autárquico, sustancial, en la gran mayoría de los casos ya no es sino una marioneta que realiza espasmódicamente los gestos que le impone el campo histórico-social: hacer dinero, consumir y "gozar' (si lo logra...). Supuestamente «libre’ de darle a su vida el sentido que quiera, en la aplastante mayoría de los casos no le da sino el «sentido' que impera, es decir el sinsentido del aumento indefinido del consumo. Su «autonomía', vuelve a ser «heteronomía', su «autenticidad' es el conformismo generalizado. (Castoriadis, 1997:80)

¿Pero de qué manera todo lo anterior puede interpretarse en relación con la experiencia latinoamericana? Según sostiene el sociólogo chileno Jorge Larraín (2005) a propósito de la formulación de Castoriadis, sería posible pensar en formas plurales de institucionalización, o de respuestas concretas a los desafíos planteados por la búsqueda de la autonomía y control racional. Comprender aquello que caracteriza a la modernidad en América Latina implicaría, por lo tanto, estudiar los parámetros culturales que contribuyeron a precisar las concreciones institucionales de estos principios ambivalentes en sí mismos y cuya relación mutua está cargada de tensiones permanentes que permiten la apertura de espacios interpretativos distintos a los europeos y norteamericanos. Acogiendo, aunque con matices importantes, el que se transformó en el ejercicio sociológico acostumbrado durante la segunda mitad del siglo $\mathrm{xx}$, Larraín plantea que toda «versión» de la modernidad depende en buena medida del proceso que la va configurando, esto es, de una «modernización» concurrente. Con todo, siguiendo de cerca la propuesta de Castoriadis, así como el trabajo de otros autores en los cuales el filósofo greco-francés influyó notablemente - Peter Wagner, Johann Arnason-, Larraín concibe al proceso de modernización en América Latina como "un campo interpretativo y, en esa misma medida, un campo de lucha por institucionalizar las significaciones imaginarias de la modernidad en un sentido determinado» (2005:26). Pese a la fuerza de su avance allí donde se presenta, buscando «concretar e implementar los valores y promesas de la modernidad en un sentido preciso", este proceso no ocurriría mediante una neutralización total de las particularidades culturales, no acontecería "a pesar de los seres humanos y sus convicciones». Por el contrario, se 
encontraría con alternativas abiertas, sensiblemente ajustadas a las interpretaciones que logren imponerse en consonancia con una identidad «local» propia.

Así, este autor considera que, si bien los procesos modernizadores principales en América Latina habrían comenzado más bien tardíamente con el logro de la independencia respecto de España, «no cabe duda que los rasgos culturales formados en los tres siglos de la colonia condicionan el carácter que sus procesos asumieron desde entonces» (34). Ahora bien, para Larraín, el proyecto de autonomía en la región mostraría una clara preeminencia durante el siglo XIX por sobre el proyecto de dominio racional, y cuando este último despega ya iniciado el siglo $\mathrm{xx}$, habría avanzado con marcado centralismo y muy dependiente del Estado. De este modo, a nivel latinoamericano habrían tenido lugar diferencias sustanciales en relación con la modernidad europea, manifestadas en distintivas respuestas de la región frente a las dimensiones problemáticas de autonomía y control "propias de toda modernidad»: una concentración del poder político no desafiada por los poderes locales, un monopolio religioso católico sin cuestionamientos de denominaciones protestantes o movimientos religiosos populares, una orientación exportadora de materias primas al comienzo que luego dio paso a una limitada industrialización promovida y dirigida por el Estado — lo que, a su vez, no dio lugar a una burguesía ni a un proletariado industrial de presencia fuerte- . Por último, tuvo lugar poder político autoritario que dejó paso a una democracia creada formalmente desde arriba, sin base de sustentación burguesa o popular y, en consecuencia, no participativa (Larraín, 2005).

Tras el quiebre del proyecto de autonomía con las dictaduras de los años setentas, entre otros efectos modernizadores relevantes — como la afirmación de la tendencia centralista autoritaria y el avance de la despolitización-, para el autor se iniciaría un cambio que se extiende hasta nuestros días, desde el modelo europeo de autonomía colectiva hacia un modelo norteamericano de autonomía individual, especialmente en países como Perú, Ecuador, México, Argentina y Chile. Señala que dentro de este modelo «los sindicatos y las organizaciones sociales se debilitan y, en general, se crea una nueva clase de ciudadanía que concibe a los ciudadanos como consumidores individuales de bienes y servicios en el mercado" (52). Con todo, pese a estas afirmaciones y a su ostensible preocupación por las prácticas actuales asociadas con la dimensión material de la vida - particularmente en Chile-, debe señalarse que la posición de Larraín destaca el "carácter concéntrico de la modernidad latinoamericana» en la cual la política habría adquirido primacía sobre las otras esferas de la sociedad — por 
ejemplo, a menudo ella prescindiría de la legalidad o, más bien, «acomoda la legalidad a sus propios intereses e impide que ella cumpla su rol en otras esferas» (50)—. Esta opinión contrasta con la de otros autores, especialmente, acerca del papel — sobre todo reciente- de la dimensión económica, que postulan incluso un virtual crecimiento fagocitador del ámbito económico sobre una disminuida dimensión política.

Tal es la versión que puede encontrarse en el trabajo de Cousiño y Valenzuela (20II), donde se plantea que desde los años noventa tendría lugar, tanto en la sociedad chilena como latinoamericana, lo que llaman «un proceso de monetarización», según el cual se impondría un sistema económico liberado de cualquier referencia sustantiva y que se encuentra exclusivamente mediado por el dinero. Ello traería aparejado el distanciamiento e incapacidad de la política de representarse a la sociedad, avanzando, en cambio, un modelo general de integración que prescinde cada vez más de la "presencia y de la conciencia reflexiva» - para comprar o vender no es necesario simpatizar o conocer las motivaciones de la contraparte- y el consiguiente extravío del vínculo social, de manera que:

No son las personas que gastan o los sujetos conscientes que se abstienen de consumir lo que cuenta para un sistema monetarizado. Solo valen las operaciones de pago que trae consigo la concepción de la economía en los términos de meras operaciones, lo que hace imposible plantear la pregunta en torno al vínculo social. Esta solo puede ser formulada desde la reflexividad del sujeto o desde la experiencia básica y no fundamentada del encuentro entre personas» (Cousiño y Valenzuela, 20Iı:I56)

Si se mira con atención, tal contexto de monetarización supone una interpretación similar a la hoy clásica perspectiva planteada por Georg Simmel (2013 [1907]) para referirse a la creciente abstracción de las relaciones sociales que genera el dinero. Se propiciaría, por la generalización de este medio de intercambio, un abandono en apariencia «liberador» de la necesidad de rendir los objetivos personales ante la sociedad, por ejemplo, a través de la sustitución de la noción de «valor» — que siempre remite al sujeto- por la de «precio», según la cual los hechos económicos dejan de encontrarse referidos a relaciones sociales asimétricas que pudiesen ser compensadas o a cualquier otro significado susceptible de ser compartido. En este sentido, precisamente por la abstracción de esas relaciones que ahora, mediante su utilización, se despegan, se «desanclan» de las obligaciones sociales anteriores, el dinero permitiría que las personas establezcan intercambios en un contexto impersonal, donde pueden poner entre paréntesis su subjetividad, una cierta idea del yo que también les sugiere una apariencia de 
autonomía, una impresión que luce emparentada con el ideal moderno de libertad.

Pero, paradójicamente, Simmel nota que este patrón consolida en forma simultánea un proceso de superior incidencia en que "la mente se encarna y simboliza en los objetos». Las relaciones sociales se encuentran, en lo sucesivo, mediadas por objetos que intentan traducir las cualidades humanas y del mundo mediante instrumentos comparables, a través de valoraciones relativas. Así, al examinar la influencia de la economía monetaria en el «mundo interior» de las personas, Simmel advierte que en esta relación tendría lugar, finalmente, una cierta decadencia de la cultura individual subjetiva frente a la expansión sin tregua de la cultura objetiva, lo que de modo muy interesante quedaría puesto en evidencia en el fenómeno del consumo: «la circulación rápida del dinero conduce a hábitos de gasto y adquisición; hace que una cantidad concreta de dinero sea psicológicamente menos valiosa y significativa, mientras el dinero en general se vuelve importante de manera creciente $^{2}[\ldots] »$ (Simmel, 1907, citado por Ritzer, 200I:339)

De esta forma, quedan también planteadas con este análisis las ilusiones del consumidor de plasmar su autonomía en una dimensión estrictamente material. Se advierte que el uso que este hace del dinero puede ser apreciado, también, solo como el comienzo de un proceso más complejo en el cual se actúa sobre una mercancía para recontextualizarla y personalizarla (Baudrillard, 2009; Sassatelli, 20I2), hasta el punto de que a esta, en algunos casos, pueda incluso no reconocérsele ya relación alguna con el mundo de los intercambios monetarios abstractos. El consumo aparece así, como una práctica primordialmente definida en relación con el ejercicio de «la elección» — de ese esquivo «sentido» en Castoriadis y que aparece aquí revestido engańosamente de materialidad, como nos recuerda Bauman-, la verdadera invitación irresistible a participar en la sublimada esfera del mercado y el signo emblemático actual inconfundible de una individualidad que desea manifestarse por medio de toda clase de señaléticas reveladoras y, a veces, incriminadoras: no querer (¿Poder?) salir de vacaciones.

\section{Repensar el consumo ante la colisión de los proyectos modernos}

Mostrando una sugerente proximidad con esta visión que plantea múltiples

2 Ritzer nota que, para este autor, parece así aplicarse también en este plano una peligrosa constante, según la cual el valor absoluto de algo parece aumentar cuando el valor de sus partes disminuye -como ocurre cuando se incrementa en tamaño y significación un grupo social, respecto de las vidas e intereses de sus miembros-. 
formas de cristalizar los proyectos de autonomía y control racional, el antropólogo argentino radicado por largo tiempo en México, Néstor García Canclini, comprende a América Latina como la compleja articulación de tradiciones y modernidades, un continente donde coexisten múltiples lógicas de interpretación y organización de la vida social y cuyo carácter distintivo es la heterogeneidad. Manifestando una percepción abierta y dúctil de la modernidad en la línea recién comentada, García Canclini la concibe constituida por las interacciones y conflictos que se producen a partir de cuatro movimientos básicos, los que identifica como un "proyecto emancipador", un "proyecto expansivo», un "proyecto renovador» y un "proyecto democratizador» (García Canclini, 1990:3I-32).

Aunque en realidad no menciona explícitamente a Castoriadis en la formulación de esta propuesta, García Canclini efectúa en la práctica un virtual desglose de aspectos constitutivos de las significaciones de «autonomía» y "control racional», como las comprende el primero. Si se observa con atención, el principio de autonomía parece ajustarse conceptualmente muy bien, de una parte, al "proyecto emancipador» descrito por el autor argentino, que concierne a una creciente "autorregulación" y "producción autoexpresiva de las prácticas simbólicas» por parte de los propios individuos, especialmente ligada en nuestros tiempos al avance del proceso de secularización. De otra parte, similar correspondencia con la significación de autonomía revela el "proyecto democratizador», que García Canclini relaciona con el impulso iniciado en la ilustración, y que promueve la educación, la difusión del arte y los saberes especializados.

Asimismo, a propósito de lo que podríamos identificar como la significación de control racional, el autor se refiere por un lado al "proyecto expansivo», que consiste en la búsqueda moderna de extender el dominio técnico, industrial y comercial, y que involucra al efecto, tanto la pretensión de aumentar los conocimientos y posibilidades de actuación sobre la naturaleza como la preponderancia que se atribuye a la conducción estratégica de la producción, la circulación y el consumo de los bienes. Por otro lado, también es posible notar la especial afinidad entre el "proyecto renovador» que García Canclini menciona y esta significación imaginaria que Castoriadis vincula con el desarrollo del capitalismo. Para el autor argentino, tal proyecto implicaría dos aspectos: la persecución de una «innovación y mejoramiento incesantes» y la «necesidad de reformular los signos de distinción desgastados (continuamente) por el consumo masificado».

Llegando a este punto se produce otro acercamiento en relación con el trabajo del filósofo greco-francés, esta vez, en torno a una cierta visión compartida 
sobre el despliegue problemático de la significación de autonomía en un contexto como el contemporáneo, esto es, de predominio de una lógica de control racional. García Canclini plantea bajo el sugerente epígrafe «La imaginación emancipada» (1990:32) que el desenvolvimiento de estos cuatro proyectos implicaría invariablemente el surgimiento de una de las más grandes «utopías» de la cultura moderna: la construcción de espacios de autonomía para el saber y la creación. Ocurriría que el desarrollo de dichos proyectos modernos acabaría siempre, en algún punto, por relacionarlos entre sí de manera contradictoria y conflictiva —el vínculo de «tensión» que también menciona Castoriadis-, causando un detrimento, en definitiva, de la atención a los objetivos asociados con los proyectos emancipadores y democratizadores. Para García Canclini, un ejemplo de lo anterior aparece en un plano de su particular interés como es el desarrollo artístico, donde el tratamiento conceptual de la cuestión de la autonomía cultural como componente que define a la modernidad, muchas veces, ha movido a los teóricos y a los propios artistas a hablar de "la cultura moderna» en forma elitista o destacando sólo diferencias y pugnas entre clases o etnias al interior de un "campo cultural», mientras que para el autor, esta dimensión hoy en día también se relaciona estrechamente y configura de manera fundamental a partir de los distintos cruces que se producen entre lo culto, lo popular y lo masivo.

La anterior, sería una de las «manifestaciones exasperadas de las contradicciones entre los proyectos modernos» (42), otra manera de entender el desajuste latinoamericano entre un "modernismo» acomodado hace tiempo en la región -la dimensión cultural y simbólica de la modernidad- y una «modernización» socioeconómica rezagada o de instalación más abierta —al decir de Larraín-. Una desbalanceada composición, útil por cierto para la preservación del estatus y privilegios de las clases dominantes, que sería distintiva de la mayor parte de nuestra trayectoria a lo largo de la modernidad y que no se habría de recombinar hasta llegados los años noventa del siglo xx. Entonces, la modernización entendida en su vertiente económica, como control racional, finalmente sobreviene con fuerza, pero por medio de la actividad de las empresas privadas y sus «iniciativas de inversión», provocando un nuevo desequilibrio que esta vez favorece una preeminencia desembozada de este último proceso.

En otras palabras, para García Canclini, desde hace algunas décadas habríamos arribado en América Latina a un contexto cultural en el cual los imaginarios «democráticos» y «emancipatorios» - tradicionalmente materializados de manera imperfecta y deficitaria, pero que antes fueron los únicos en escenaquedaron finalmente situados a la saga de 
aquellos proyectos «expansivos» $\mathrm{y}$ «renovadores». En este sentido, la socialización profunda o democratización de la cultura seguiría pendiente $y$, mientras tanto, la desigualdad en la apropiación de bienes simbólicos y en el acceso a la innovación cultural quedaría virtualmente entregada al arbitrio de la economía. Así, para el autor no resultaría extrańo que la mirada política sobre la convivencia se encuentre desacreditada por el propio mercado, tanto porque este último habría mostrado una eficacia superior para organizar las sociedades - con los costos mencionados—, como a raíz de que aquel habría «devorado» a la política, sometiéndola «a las reglas del comercio y la publicidad, del espectáculo y la corrupción».

Lejos de desanimarlo, este diagnóstico empuja con más fuerza a García Canclini a examinar lo que el mercado y la globalización «tienen de cultura», invitándolo a profundizar hasta una dimensión elemental de estos procesos donde pervive, aún con opacidad, la relación social. En otras palabras, se aprecia aquí un tránsito fluido desde un diagnóstico más bien adverso - similar al que antes habíamos descrito acudiendo a otros autores- hacia un plan de actuación provisto de un acento distinto, en cierto modo, prometedor. $\mathrm{Al}$ examinar la construcción de su propuesta en torno al consumo (véase, 1992, 1995, 2005), puede notarse que el aprendizaje clave obtenido por García Canclini a partir de su estudio de la obra de autores como Douglas e Isherwood (1990) o Bourdieu (2003), expresado en su conocida afirmación acerca de qué "el consumo sirve para pensar» — su versión del aserto «las mercancías sirven para pensar» de Douglas e Isherwood-, se refiere a una forma de comprender la convivencia en las sociedades contemporáneas como sustentada en una necesaria articulación de distintas orientaciones en torno a la cultura, las cuales demandan reconocimiento, se sirven, al efecto, de objetos y bienes culturales y siempre se encontrarían demarcadas como un conjunto específico de similitudes en relación con la sociedad que las contiene, mientras, al mismo tiempo, estarían dispuestas en una relación comunicativa con los demás proyectos existentes.

En este sentido, García Canclini nota patrones de integración cultural asociados al consumo que, cada vez con mayor fuerza, serían la expresión de un escenario global donde la relación con el mercado también otorga un sentido de pertenencia a los individuos y es capaz de conformar comunidades, en ocasiones transterritoriales y multilingües. Para García Canclini, se trata de un aspecto que de suyo afecta en forma determinante aquello que nos hace miembros de una comunidad política y que en su opinión debe redefinir la concepción de ciudadanía, ahora entendida principalmente como identidad cultural. Pero, si esas identidades «se estructuran menos 
desde la lógica de los Estados que de los mercados", será preciso, entonces, pensar en los rumbos potestativos y públicos que actualmente sigue el consumo, lejos de concebirlo al modo tradicional, como un hecho más bien impulsado hacia la esfera privada. Nuevos asideros surgen así para las exigencias de transformaciones sociales y políticas, donde el avance de los procesos de democratización sería evaluado crecientemente, también, conforme al cumplimiento de las reglas que protegen los distintos consumos en la sociedad, esto es, mediante "garantías de acceso a servicios», «información veraz», «no discriminación», «reparación», etc.

Por cierto, ello obligaría a que la abstracción universalista de la propia noción de consumidor y que está igualmente presente al hablar de colectivos de consumidores, comience a mostrarse cada vez mejor conectada con la configuración legal de nuestras sociedades. Es así que, particularmente en contextos de interculturalidad creciente y persistencia de desigualdades, el autor se encuentra muy consciente de que los atributos sociales que portan consigo los consumidores - de clase, etnia, género, edad, etc.—, representan hoy aspectos que afectan la solidez de esta noción de la ciudadanía y que requieren un tratamiento impostergable si lo que se busca es asegurar la eficacia de esos derechos leídos desde el consumo y de las concurrentes garantías en cuanto a su ejercicio justo y autónomo.
Si se observa con cuidado, a propósito de esta visión de la ciudadanía, García Canclini también explora la idea — antes mencionada-de consumo como una forma de producción de valor que transforma al objeto en cultura vivida, donde se actúa sobre la mercantilización y en ocasiones se la subvierte (García Canclini, 2008). Tal es el caso de los intentos de rectificar determinadas arbitrariedades del mercado en las condiciones de extracción y fabricación, o en las transacciones comerciales, por ejemplo, mediante la elección de bienes alternativos asociados al comercio justo, o bien, con el boicot de determinados consumos.

Es interesante notar que esa preocupación por el consumo como articulador de nuevos tipos de identidades daría cuenta, según García Canclini, de formas de comprender y "procesar» socialmente las fisuras y entresijos instalados en nuestras sociedades a partir de una definición problemática de los sentidos de pertenencia. Pero, de acuerdo con lo que venimos afirmando, quizás resulte más interesante aún, descubrir que en esa mirada subyace una apuesta acerca de formas no ensimismadas de sobrellevar la aspiración moderna de realización, autonomía y dignidad, esta vez, a propósito del posible impulso en nombre del consumo de espacios asociativos y de cooperación social.

No se discute con ello que, igualmente, pueda encontrarse planteada 
aquí una posición «transaccional» de la modernidad latinoamericana, asimismo, presente en la aguda metáfora de «la deuda» bosquejada por Sarlo (200I) para referirse a «la forma actual de la realización incompleta de nuestra vida en sociedad", con naciones modernas que nacieron sobre la base de promesas - los proyectos mencionados- que transformaron a sus miembros en acreedores de un crédito proporcionado al Estado, y a cuyo cumplimiento este se encontraría obligado para ser reconocido legítimamente. "Consumo», "deuda», nociones que aun con sus generalidades e imprecisiones, sin embargo, comparten el acierto de no pensar a los ciudadanos de un modo exclusivamente abstracto, sino también desde esa materialidad donde residen las necesidades y que persiguen las expectativas, ahí donde además se gesta una parte del clamor que hoy en día se manifiesta pulsátil en las calles de varios de nuestros países.
En conclusión: la disposición y, sobre todo, la elección de bienes, se encuentran sensiblemente vinculadas con las promesas de realización y autonomía de la modernidad — de la nuestra y de la modélica-. En nuestras sociedades, las opciones del consumo «tienen valor político en sentido lato", en tanto que son medios de inclusión y exclusión social, un espacio donde la persona no solo tiene la posibilidad, sino la obligación cultural de expresarse lo más libremente posible. La relación del consumo con las grandes utopías modernas no es baladí: opera en los hechos como una fuerza impulsora de conciencias y prácticas, de procesos de constitución de la identidad social, ya no de un individuo que desaparece en medio de la colectividad en sociedades (semi)industrializadas, sino de nuevas comunidades definidas por su dimensión cultural y la necesidad que tienen de un marco de pluralismo democrático y justicia.

Referencias bibliográficas

- BAUDRILLARD, J. (2009). La sociedad de consumo: sus mitos, sus estructuras. Madrid: Siglo XXI.

- BAUMAN, Z. (2000). Trabajo, consumismo y nuevos pobres, Barcelona: Editorial Gedisa.

- BOURDIEU, P. (2003). La distinción. Criterios y bases sociales del gusto. Madrid: EditorialTaurus.

- CASTORIADIS, C. (1975). La institución imaginaria de la sociedad. Barcelona: Tusquets Editores. 
. (1997) El avance de la insignificancia. Buenos Aires:

Eudeba.

(2008). El mundo fragmentado. La Plata. Argentina:

Terramar Ediciones.

- CHANEY, D. (1996). Estilos de vida. Madrid: Talasa.

- COUSIÑO, C. y VALENZUELA, E. (2011). Politización y monetarización en América Latina. Santiago: Instituto de Estudios de la Sociedad.

- CRISTIANO, J. (2012) Lo social como institución imaginaria. Castoriadis y la teoría sociológica. Argentina: Eduvim.

- DOUGLAS, M. e ISHERWOOD, B. (1990). El mundo de los bienes. Hacia una antropología del consumo. México: Grijalbo.

- DUSSEL, E. (2012). Hacia una filosofía política crítica, en Obras Selectas XXIII. Buenos Aires: Docencia.

- ESCOBAR, A. (2003). Mundos de conocimiento de otro modo. El programa de investigación de modernidad latinoamericano (pp.51-80). En Tabula Rasa, enero-diciembre, N.001, Colombia.

- GARCÍA CANCLINI, N. (1990). Culturas híbridas. Estrategias para entrar y salir de la modernidad. D.F., México: Grijalbo (1992). Los estudios sobre Comunicación y Consumo: El Trabajo Interdisciplinario en Tiempos Neoconservadores. En Diálogos de la comunicación, No. 32.

- _ (1995). Consumidores y ciudadanos. Conflictos multiculturales de la Globalización. México: Grijalbo.

• ___ (2005). Diferentes, desiguales y desconectados. Mapas de la interculturalidad. Barcelona: Gedisa. (2008). La globalización imaginada. Buenos Aires:

Paidós.

- LARRAÍN, J. (2005). ¿América Latina moderna?. Globalización e identidad. Santiago de chile:Lom ediciones.

- QUIJANO, A. (2001). Colonialidad del poder. Cultura y conocimiento en América latina. En El Eurocentrismo y la filosofía de la liberación en el debate intelectual contemporáneo (pp.117-132), Duke University, Ediciones del signo, Argentina.

· RITZER, G. 2001. Teoría sociológica clásica, Madrid: McGraw Hill. 
- SARLO, B. (2001). Tiempo presente: notas sobre el cambio de una cultura. Buenos Aires: Siglo XXI.

- SASSATELLI, R. (2012) Consumo, cultura y sociedad. Buenos Aires: Amorrortu.

- SIMMEL, G. (2013) Filosofía del dinero. Madrid: Capitán Swing. 